\title{
Focus Group 3 - Schooling, school culture, organisation of the school, school in the information- rich society
}

Chair: Peter Bollerslev (Denmark)

Rapporteurs: Gail Marshall (US) and David Passig (Israel)

Participants: Miguel Aliaga (Chile), Eduardo Cabezon (Chile), Wendy

Davies (UK), Jimmy Isaac (India), Jaap Westbroek (Netherlands), Kwok-Wing Lai (New Zealand)

Keywords: Vision, knowledge, wisdom, school

\section{INTRODUCTION}

The theme of school, the culture of the school, and the organisation of the school in the information rich society energised the Focus Group to consider visions of education that would apply to the many different cultures and many different goals.

\section{VISIONS OF THE FUTURE}

Moving into the future, the Focus Group agreed, called for a future oriented vision. While this might seem to be self-evident, a discussion of Schools of the Future must, after all, engage in discussions of the future, the Focus Group believed that it was important to begin with what should be and must be in the future instead of an alternative approach which would begin with the present, state the problems and prospects of present practice, and then work toward ameliorative plans and programs that would push toward some eventual goals. Similarly, the Focus Group believed that it was 
important to establish a vision that had a far reaching time span-ten-twenty, thirty or more years ahead-rather than discussing a future three or four years from now, the standard frame of reference of hardware and software providers. Similarly, the Focus Group agreed that the scope of the schools' work should be as broadly defined as possible, and goals should be directed toward many different types of school activities, policies and practices while all of those must be global in their focus and impact.

Such a broadly based vision calls for the highest degree of human interaction. So the Focus Group said that in order to achieve its vision the school of the future must strive to achieve co-ordination and connectivity in order to create new knowledge from the old, yielding wisdom, which is acquired through collaboration.

Such a dynamic, comprehensive vision calls for a re-conceptualisation of many different but vital components of schools: their architecture, their timetables, and the types of accountability measures used. Similarly, current ideas about appropriate uses of technology must be broadened and each country's culture of schooling and of change will need to be re-examined and/or changed. Part of that culture, the role and the dynamics of the "youth culture" in each country, must be analysed with a view toward understanding the ways youth engage themselves in knowing and learning, and the ways that such engagements develop and grow.

It would be utopian to expect that such visions could be achieved without discussion and debate. For example, it is certainly the case that from one country to another and within countries there are dualisms-idealism vs. utilitarianism and the economy as a constraint vs. the economy as a reality. Similarly, looking to the future must address the question of whether a school is a "physical entity" or is an "idea" situated in many different places at many different times. But, while recognising that there would be inevitable debates about key issues, the Focus Group believed that peoples around the world would accept and adopt visions that moved from knowledge acquisition to wisdom attainment. Key factors in knowledge acquistion are students' interests, skills and roles, teachers' competencies, beliefs and roles, and the community's goals, beliefs and resources. Key goals of wisdom attainment are the engagement of students in authentic, important learning, the involvement of teachers with students, the community and each other, and the community's investments toward change.

Toward those ends, both the acquisition of knowledge and the attainment of wisdom call for models of change, even when those models have been shown to have been unsuccessful because lessons can be learned from both successful and unsuccessful change efforts. Moving towards knowledge and wisdom also calls for strategies for sharing stories of change, and 
understanding what we are moving from, where we are going and why. Visions for the future also call for identifying the scaffolding needed for change. Similarly, as schools look to the future there must be an understanding of why schools today are designed and organised as they are in order that the implications of past practice may inform future policies.

Since the creation of schools of the future will be more broadly based than today's schools, the Focus Group also agreed that future schools' planning will call for an understanding of the relation between humans but, equally important, will call for an understanding of the relation between humans and nature.

\section{METAPHORS FOR THE VISION}

It is often difficult to convey a vision in words but metaphors have the power to make comparisons that are visual and/or vital, and so the Focus Group thought of metaphors as a means of conveying the breadth and depth of their vision. Discussions of the ways schools around the world planned for change and the types of schools resulting from the plans led to descriptions of what "school" meant in different cultures. In Sanskrit "school" means "an abode of knowledge"; in Danish "school" has the meaning of "a direction toward a vision" and in China, "a place for acquiring the knowledge of how to behave." Chile envisions school as a community of actors participating in a social enterprise while in Israel the school is " the house of the book""beit hasefer." All of the metaphors connoted a process as well as a place where knowledge and wisdom can be attained, and so the Focus Group agreed that such metaphors encapsulated the essence of their vision for the School of the Future - places where students, teachers, and the community would engage in activities directed toward wisdom. 